\title{
Editorial
}

\section{Extrapulmonary Manifestations of COVID 19: A Call to Extra Vigilance and Tribute to Dr Li Wenliang}

\author{
Onoja AM${ }^{1}$, Jombo GTA ${ }^{2}$, Onoja AT $^{3}$ Nwannadi AI $^{1}$, Aba IH ${ }^{1}$, \\ ${ }^{I}$ Department of Haematology and Blood Transfusion, College \\ of Health Sciences, Benue State University, Makurdi Nigeria. \\ ${ }^{2}$ Department of Microbial Pathology, University of Medical \\ Sciences, Ondo-City, Nigeria.
}

${ }^{3}$ Department of Medical Microbiology, University of Agriculture, Makurdi, Nigeria.

\author{
Correspondence \\ Dr. Onoja $A M$ \\ Email: doconoja@gmail.com \\ Tel: $\quad+2348160669376$
}

\begin{tabular}{ll}
\hline Article Metrics & \\
Date submitted: & $01 / 06 / 2020$ \\
Date Accepted: & $13 / 06 / 2020$ \\
Date Published: & June, 2020
\end{tabular}

\begin{abstract}
COVID-19 pandemic has covered all continents and virtually all countries of the world infecting millions of people with several hundred thousands of death. It was first brought to the attention of a Chinese ophthalmologist Dr Li Wenliang. The disease which was first believed to be solely associated with the lungs and respiratory system has now shown that the spectrum of organ involvement of the disease is much larger than earlier believed. While lung and pulmonary features still account for a much larger presentation of the disease, other clinical manifestations such as fulminant myocarditis, arteriovenous thromboembolism, disseminated intravascular coagulopathy, intracerebral haemorrhage, diarrhea, hypoxic encephalopathy, septicaemia and detection of SARS-CoV-2 particles in stool, saliva and semen of infected individuals are also becoming less infrequent. Haematologic manifestations of hypercoagulable blood are commonly reported among hospitalized COVID-19 patients. An elevated D-Dimer, that is rising in the course of disease may signifies disease deterioration. Prolonged PT and aPTT and increased fibrin degradation products with severe thrombocytopenia have been associated with life threatening disseminated intravascular coagulation (DIC). Physicians should therefore be on a watch out for these features in the management of patients and be ready to spot out other new surprises by the disease. This should be through deepening of curiosity by health personnel in the assessment and management of patients to spot out early surprises of COVID-19 to strengthen the sustenance of the ongoing control of the pandemic
\end{abstract}

Keywords: COVID-19, Extra-pulmonary, Presentations, Li Wenliang, SARS-CoV-2

\section{BACKGROUND}

t was Dr Li Wenliang an Ophthalmologist in the city of Wuhan famous for strong clinical judgments among colleagues that first raised an alarm of new respiratory virus disease on $30^{\text {th }}$ December 2019. In his group chat he wrote "A new coronavirus infection has been confirmed and its type is being identified. Inform all family and 
Onoja AM, Jombo GTA, Onoja AT, Nwannadi AI, Aba IH,

relatives to be on guard," and the disease eventually took his life at the age of 34 years. Li contracted SARS-CoV-2 infection while treating an infected glaucoma patient and was hospitalized on $12^{\text {th }}$ January, 2020, and later on moved to ICU. His last post from ICU publicly declaring his COVID-19 result "Today my test has come back positive, the dust has settled, I have finally been diagnosed." came on February $1^{\text {st }} 2020$, shortly after which his ventilator was disconnected due to rapid irreversible deterioration!. As at $8^{\text {th }}$ of May, 2020, COVID19 has infected over 3.85 million people with at least 270,000 deaths globally, and in Nigeria the official infection rate stands at 3,526 people with 107 deaths $^{1-3}$.

\section{Usual Presentations}

At the outset COVID-19 was generally believed to be a respiratory disease as almost all patients presented with pulmonary symptoms and clinical investigations primarily targeted the lungs and the respiratory system presenting with dry cough, chest pain and difficulty in breathing. The common radiologic and computerized tomographic features include: peripheral patchy lesions or consolidation, halo signs, air bronchogram sign, patchy ground glass opacity among others. This belief has led to the deployment of all prognostic and disease monitoring apparatuses targeting the lungs and respiratory system with little attention towards monitoring of other organ systems that may be as well seriously damaged. This could explain the reason why ventilators often fail to revive some severely ill in ICUs as the underlying pathologies may be extra-pulmonary. ${ }^{4.8}$

\section{Extra-pulmonary and Unusual Presentations}

COCID-19 can present in form of nasal congestion and loss of smell, sore throat, muscle pain and malaise. In a study carried out in China it was found that diarrhea is also not an uncommon finding in SARS-CoV-2 infections. Other clinical features such as mild fever and headache could easily be diagnosed and treated as malaria or one of the enteric fevers especially where there is concurrent blood smear positive for malaria and high widal tests titres as well. ${ }^{9-11}$ The situation may become compounded when there are no facilities to quickly screen such patients and establish early diagnosis as is the case in most parts of Nigeria and entre sub-saharan Africa, hence fueling uninterrupted community spread of COVIS- $19 .{ }^{12}$

Other studies have shown that COVID-19 patients have presented with the following clinical patterns: fulminant myocarditis, venous thromboembolism, diarrhea, intracerebral haemorrhage, hypoxic encephalopathy, septicaemia, detection of SARS-CoV-2 particles in stool, saliva and semen of infected individuals ${ }^{13-17}$. This may not be the end of the list as other forms of unusual and extrapulmonary presentations of COVID-19 are probably still ahead.

Haematologic manifestations of hypercoagulable blood is commonly reported among hospitalized COVID-19 patients. An elevated D-Dimer, that is rising in the course of disease may signifies disease deterioration. ${ }^{20}$ Prolonged PT and aPTT and increased fibrin degradation products with severe thrombocytopenia have been associated with life-threatening disseminated intravascular coagulation (DIC). ${ }^{20}$

It has also been established in many reports that COVID-19 infected patients, whether hospitalized or ambulatory, have very high risk of venous thromboembolism, the reports also recommend early and prolonged thromboprophylaxis with low molecular weight heparin.

Isolation of SARS-CoV-2 in stool samples clearly shows that environmental sanitation requiring eradication of surface and open air defaecation has become mandatory along with defaecation in trenches and canals before community spread of the disease can be halted. Also its presence in the saliva of asymptomatic carriers brings up the needs to health educate on implications on some of the social practices such as kissing in this wave of COVID-19. In the same vein detection of SARS-CoV-2 in semen potentially could lead to sexual transmission of the virus, and its short and long term impacts on sperm count and fertility of infected individuals need to be ascertained. Adequate sex education may therefore be needed in the global campaign package against COVID- $19 .{ }^{18,19}$ 
Presentations of cardiac, hepatic, vascular, cerebrovascular, nephritogenic, and gastrointestinal pathologies at specialty as well as Primary Health Care (PHC) clinics should not be taken in isolation during this period of COVID-19 pandemic and possibly in the foreseeable future COVID-19 status of such patients should be clearly established to rule out remote possibilities of any association.

In conclusion while it appears we may have known so much about SARS-CoV-2 over a very short period of time, the scientific world should be open to surprises that may be thrown up by this same virus as it appears more still needs to be known. Medical doctors and other health professionals should sharpen their curiosity in patient assessment and management so as to detect early some of the evolving unusual presentations of the disease to strengthen control of the pandemic. A strong sense of clinical judgment as displayed by late Dr Li Wenliang which alerted the world of a pending catastrophe should be demonstrated by all health professionals in this $21^{\text {st }}$ century to guarantee continuous human existence on the planet.

\section{REFERENCES}

1. Peterson E, Hui D, Hamer DH, et al. Li Wenliang, a face to the frontline healthcare worker. The first doctor to notify the emergence of the SARS-CoV-2, (COVID-19), outbreak. Int J Infect Dis. 2020; (93): 205-207. DOI:https://doi.org/10.1016/j.ijid.2020.02.052.

2. Yi Y, Lagniton PNP, Ye S, Li E, Xu RH. COVID-19: what has been learned and to be learned about the novel coronavirus disease. Int J Biol Sci. 2020; 16(10):1753-1766. doi:10.7150/ijbs.45134. Available from http://www.ijbs.com/v16p1753.htm.

3. Rabi FA, Al Zoub MS, Kasasbeh GA, et al. SARS-CoV-2 and Coronavirus Disease 2019: What We Know So Far. Pathogens 2020, 9(3), 231; https://doi.org/10.3390/pathogens9030231.

4. Lee EYP, Ng MY, Khong PL. COVID-19 pneumonia: what has CT taught us? Lancet Infect Dis. 2020; 20(4): 384-385.

DOI:https://doi.org/10.1016/S14733099(20)30134-1.

5. Cascella M, Rajnik M, Cuomo A, et al. Features, Evaluation and Treatment Coronavirus (COVID-19) [Updated 2020 Apr 6]. In: StatPearls [Internet]. Treasure Island (FL): StatPearls Publishing; 2020; https://www.ncbi.nlm.nih.gov/books/NBK5547 76/.

6. Adhikari, S., Meng, S., Wu, Y. et al. Epidemiology, causes, clinical manifestation and diagnosis, prevention and control of coronavirus disease (COVID-19) during the early outbreak period: a scoping review. Infect Dis Poverty. 2020; 9(29): https://doi.org/10.1186/s40249-020-00646-X.

7. Tian S, Hu W, Niu L, et al. Pulmonary Pathology of Early-Phase 2019 Novel Coronavirus (COVID-19) Pneumonia in Two Patients With Lung Cancer. J Thoracic Oncol. 2020; 15(5): 700-704. https://doi.org/10.1016/j.jtho.2020.02.010.

8. Vetter P, Vu Diem L, L'Huillier AG, et al. Clinical features of covid-19. BMJ 2020; 369: :m1470. doi: https://doi.org/10.1136/bmj.m1470.

9. Jombo GTA, Mbaawuaga EM, Ayegba AS, Enenebeaku MNO, Okwori EE, Peters EJ, Akpan S, Odey F, Gyuse AN. How far have we rolled back malaria on the African continent nine years down: The burden of malaria among pregnant women in a semi-urban community of northern Nigeria. J of Med and Med Sci. 2010; 1(6): 235-241. http://www.academicjournals.org/IJMMS..

10. Jombo GT, Mbaawuaga EM, Ahmed U, Abba PO. Patterns of Widal test results among patients suspected to have typhoid fever attending BSUTH Makurdi Nigeria. Int J 
Onoja AM, Jombo GTA, Onoja AT, Nwannadi AI, Aba IH,

Health Sci Res. 2019; 9(1):6-12.

www.http://www.ijhsr.org.

11. Jombo GTA, Denen Akaa P, Banwat EB, Dauda MA. A review of literature on unusual clinical presentations and potential challenges in diagnosis of histoplasmosis. J of Clin Medi and Research 2010; 2(10): 159-160.

http://www.academicjournals.org/JCMR.

12. Jombo GTA, Mbaawuaga EM, Denen-Akaa P, Alao OO, Peters EJ, Utsalo SJ, et al. Socio-cultural factors influencing the control of malaria in an endemic city in north central Nigeria. Int J of Biol and Med Research 2010; 1(4): 172-176. http://www.biomedscidirect.com/articles.php.

13. Sharifi-Razavi A, Karimi N, Rouhani N. COVID-19 and intracerebral haemorrhage: causative or coincidental. New Microbes \& New Infections. 2020; 35C: 100669.

14. Gu J, Han B, Wang J. COVID-19: Gastrointestinal manifeststions and potential faecal-oral transmission. Gastroenterol. 2020; 158: 1518-1519.

15. Chen T, Wu D, Chen H, Yan W,. Clinical characteristics of 113 deceased patients with coronavirus disease 2019: retrospective study. BMJ. 2020; 368: m1091.

16. Zeng JH, Liu YX, Yuan J, et al. First case of COVID-19 complicated with fulminant myocarditis: a case report and insights [published online ahead of print. Infection. 2020;1-5. doi: https://www.10.1007/s15010-020-01424-5.

17. Lodigiani C, Lepichino G, Carenzo L,. Venous and arterial thromboembolic complications in COVID-19 patients admitted to an academic hospital in Milan, Italy. Thrombosis Resaerc 2020; 191: 9-14.

18. Rana P. Coronavirus Is Found in Semen of Covid-19 Patients. Wall Street J.

https://www.wsj.com/articles/coronavirus-is-foundin-semen-of-covid-19-patients-11588863600.

Acessed 8th May, 2020.

19. Greenwood M. Saliva samples preferable to deep nasal swabs for testing COVID-19. YaleNews. https://news.yale.edu/2020/04/24/saliva-samplespreferable-deep-nasal-swabs-testing-covid-19. Accessed 8th May, 2020.

20. Terpos, E, Ntanasis-Stathopoulos, I, Elalamy, I, Hematological findings and complications of COVID-19. Am J Hematol. 2020; 1- 14. https://doi.org/10.1002/ajh.25829 